\title{
ANÁLISE DOS ASPECTOS AMBIENTAIS NA REGIÃO DE SANTA CECILIA - SP, NA BACIA MICRO-HIDROGRÁFICA DO CÓRREGO ANHANGUERA
}

\author{
Arqa . Profa. Dra. Pérola Felipette Brocaneli \\ Enga . Profa. Dra. Monica Machado Stuermer \\ Arq $^{a}$. Carolina Gomes \\ Arqa. Barbara de Souza
}

\begin{abstract}
Resumo
O presente trabalho busca a caracterização ambiental, em alguns aspectos relevantes, sendo estes a vegetação, a hidrografia e a banda termal da região locada no bairro de Santa Cecília. O estudo da vegetação se deu através da observação e analise de foto aérea da região, demarcando as áreas verdes. Para a análise da hidrografia, a área de estudo foi sobreposta ao mapa de micro bacias do município de São Paulo, de onde se observou em qual micro bacia se localiza a área de estudo. O estudo da temperatura se deu através do mapa da banda termal disponível no Atlas Ambiental do Município de São Paulo. As análises dos dados revelam uma região com baixa qualidade ambiental, nos aspectos estudados, e mostra a relevância das questões ambientais, na gestão dos espaços públicos, no que tange o estudo das mudanças climáticas relacionadas à qualidade de vida do cidadão residente ou usuário da área.
\end{abstract}

Palavras-chave: mudanças climáticas, vegetação, hidrografia, temperatura, Santa Cecília 


\title{
ANALYSIS OF ENVIRONMENTAL ASPECTS IN THE REGION OF SANTA CECILIA - SP, IN THE MICRO WATER BASINS OF THE STREAM ANHANGUERA
}

\begin{abstract}
This work aims the environmental characterization, in some aspects such as vegetation, hydrography and thermal band of the region inside the district of Santa Cecília. The study of vegetation occurred through observation and analysis of aerial photo of the region, marking the greens. For the analysis of the hydrography, the study area was superimposed on the map of micro basins of São Paulo, observing in which microbasin the areas was located. The study of temperature occurred through the map of thermal band available in Environmental Atlas of São Paulo. The data analysis revealed a region with low environmental quality in the studied aspects and showed the relevance of environmental issues in the management of public spaces, with respect to environmental changes and quality of life of the resident or users of the area.
\end{abstract}

Keywords: environmental changes, vegetation, hydrography, temperature, Santa Cecilia

\section{INTRODUÇÃO}

A questão das mudanças climáticas apresenta-se como principal contexto de diferentes pesquisas que buscam melhorias urbanas relacionadas ao adensamento urbano, ao crescimento populacional, a correção de danos ambientais, a recuperação de alguns ecossistemas e ainda desenvolver a sustentabilidade ambiental, econômica e social explorando as relações entre os homens e o meio ambiente, enfocando a preservação dos recursos naturais e a melhoria da qualidade de vida nas cidades.

A análise ambiental do território como ferramenta para sua ocupação se mostra de grande importância para um desenvolvimento urbano ecologicamente correto que reconhece as aptidões e limitações do território. Nucci (2008) coloca que um estudo completo para identificação das características ambientais só poderia ser feito por uma equipe multidisciplinar, capaz de levantar e trabalhar com todas as variáveis ambientais existentes, tais como solo, vegetação, proteção de várzeas e áreas úmidas, qualidade de ar e água, resíduos, ruído, conforto térmico e educação ambiental. As- 
sim, este trabalho apresenta limites em sua extensão, relacionados com questões de exeqüibilidade. Os aspectos ambientais contemplados neste estudo foram a vegetação, a hidrografia e a banda termal da região, em função da disponibilidade de dados e tempo de pesquisa.

A cidade de São Paulo, parte do bioma da mata atlântica - antes da instalação do cenário urbano - apresentava intensa biodiversidade, com flora e fauna integradas à paisagem natural, onde inicialmente havia grande riqueza em água doce, encontrada em rios e córregos - como em poucos territórios - devido à profusão de nascentes entremeadas a um "mar de morros"(1). As águas provenientes de nascentes nas terras altas foram responsáveis pela formação e manutenção de inúmeros rios e córregos que se espraiavam em planícies e várzeas compondo as áreas úmidas das terras baixas da região.

No entanto, o processo de urbanização, ocorrido a partir dos anos 60 , trouxe como conseqüência a supressão da vegetação, a impermeabilização do solo, reduzindo, drasticamente, o sistema de armazenamento natural das águas. Acrescenta-se a esse problema a prática de canalizações dos rios e córregos que alterou o comportamento das bacias hidrográficas, exigindo cada vez mais medidas para disciplinar e conter as águas (BROCANELI e STUERMER, 2006) e alterando o ecossistema local, criando uma série de impactos ambientais, sentidos, nos dias atuais, na qualidade vida urbana.

\section{OBJETIVOS}

Em um contexto contemporâneo de mudanças climáticas, o objetivo deste trabalho é o entendimento e a caracterização ambiental, em alguns tópicos selecionados, dentro do distrito de Santa Cecília, em uma área pré-determinada, buscando:

1 Averiguar a condição ambiental da área estudada, no que tange aos aspectos escoIhidos para analise;

2 Identificar a tipologia da organização e espacialidade das áreas verdes no perímetro estudado; 
3 Analisar as porcentagens de áreas verdes na área de estudo, e verificar se estas são adequadas a boa qualidade de vida dos habitantes e usuários da região.

\section{METODOLOGIA}

Para o desenvolvimento desta pesquisa foi feito o levantamento e análise de bibliografia especifica sobre o assunto, bem como análise de dados e mapas disponibilizados pela Prefeitura Municipal de São Paulo_PMSP. Foram também utilizadas fotos aéreas disponíveis em sites idôneos e o limite da bacia hidrográfica, na qual a área se insere. Foi considerado como o limite maior para a análise dos aspectos ambientais, critério definido por Odum (1988) que considera a bacia hidrográfica a menor unidade de gestão ambiental.

Sobre os mapas foram identificados perímetros de estudo e informações relevantes, sendo que:

1 Para análise da vegetação foram identificadas e espacializadas, as manchas verdes segundo os critérios definidos por Jim (1989) e Dramstad, Olsom e Formam (1996);

2 A análise da hidrografia ficou restrita a sobreposição das informações encontradas, nas diferentes bases cartográficas, seguindo a metodologia do Planejamento Ambiental definida por lan L. McHarg (2000);

$3 \mathrm{~A}$ análise da temperatura ateve-se a sobreposição dos diferentes limites sobre a banda termal do município de São Paulo, disponível no Atlas Ambiental do município, também seguindo a metodologia do Planejamento Ambiental definida por lan L. McHarg (2000);

\section{ÁREAS VERDES}

Os espaços verdes públicos desempenham um importante papel dentro de uma maIha urbana em reconstrução, assim, sua localização, seus acessos, qualidades e potencialidades, devem ser bem estudadas, estabelecidas e implantadas. 
A configuração e quantidade ideal de áreas verdes e principalmente áreas verdes públicas na malha urbana é muito discutida. Embora sua presença seja inquestionável e necessária, as diversas tipologias existentes nos mostram diferentes soluções e nos levam a encontrar os seguintes índices: áreas públicas/habitante, áreas verdes/ habitante e áreas verdes públicas/habitante. Estes índices divergem entre as cidades, estados e países, devido à uma grande ou baixa urbanização e a não preservação de áreas naturais.

Existem relatos de estudos de índices ideais de "área verde/habitante", porém são vagos e divergem entre si, não estipulando e definindo o real conceito de "áreas verdes", se estas são realmente consideradas áreas verdes, ou seja, "constituídas de pelo menos 70\% do seu espaço por áreas vegetadas com solo permeável" (GUZZO, CARNEIRO, JÚNIOR: 2006), e também a porcentagem que, dessas áreas verdes relacionadas, são realmente acessíveis aos usuários e apresentam significativo papel na preservação dos ecossistemas naturais, ou seja, que promovam uma conexão com as demais áreas verdes e áreas de preservação do entorno, conforme previsto pela "Teoria dos Ecossistemas" proposta por Dramstad, Olson e Forman (1996).

Ao analisar esses relatos, encontra-se uma dúvida, que embora uma cidade ou área possua esses "níveis mínimos sugeridos" como ideal de área verde/habitante, quanto dessa área seria realmente de acesso público e forneceria as necessidades desejadas por seus usuários? (GUZZO: 1999; GUZZO, CARNEIRO, JÚNIOR: 2006; NÁDIA, SHIMBO, IOSHIAQUI: 2008.)

"Ainda em relação aos índices é importante comentar que está difundida e arraigada no Brasil a assertiva de que a ONU ou a OMS, ou a FAO, considerariam ideal que cada cidade dispusesse de $12 \mathrm{~m}^{2}$ de área verde/habitante

(TROPPMAIR, 1989; LOMBARDO, 1985 e GEISER, 1975).

"Nas pesquisas, por carta, que fizemos junto a essas organizações, foi constatado que este índice não é conhecido, como não o é, entre as faculdades de paisagismo da República Federal da Alemanha. Somos levados a supor, depois de termos realizado muitos estudos, que esse índice se refira tão somente às necessidades de parque de bairro e distritais/setoriais, já que são os que, dentro da malha ur- 
bana, devem ser sempre públicos e oferecem possibilidade de lazer ao ar livre." (CAVALHEIRO, DEL PICCHIA: 1992)

"Em termos de Brasil, uma referência que devemos ter como guia para avaliação da qualidade urbana em função da oferta de espaços livres é a da 'Carta a Londrina e Ibiporã' (SBAU, 1996) na qual, após conferências entre pesquisadores e especialistas, é divulgado o padrão mínimo de $15 \mathrm{~m}^{2} /$ hab de espaços livres dedicados ao lazer. Observa-se aqui o termo 'lazer' que revela o cuidado da SBAU em diferenciar os vários tipos e funções dos espaços livres, excluindo desse índice aqueles espaços qualificados como verde viário, cemitérios, hortas ou unidades de conservação."

(FONTES, CARVALHO: 2008)

Portanto, a fim de entender e estipular os índices de espaços livres, verdes, públicos/ habitante, entre outros, de qualquer região determinada, deve-se primeiramente obter a definição de cada termo em questão, sendo que os índices mais utilizados são:

- índice de cobertura vegetal, que á a \% de área urbana coberta por vegetação; índice de espaços livres ( $\left.\mathrm{m}^{2} / \mathrm{Hab}\right)$, que é a relação entre valor de área destinada a espaços livres e população residente;

- índice de espaços livres públicos ( $\left.\mathrm{m}^{2} / \mathrm{Hab}\right)$, que é a relação entre valor de área destinada a espaços livres públicos e população residente;

- índice de áreas verdes ( $\left.m^{2} / \mathrm{Hab}\right)$, que é a relação entre valor de área caracterizada como área verde e população residente;

- índice de áreas verdes públicas ( $\left.m^{2} / \mathrm{Hab}\right)$, que é a relação entre valor de área caracterizada como área verde pública e população residente.

O sistema de áreas verdes de uma cidade deve incluir remanescentes expressivos de vegetação nativa, protegidos em Unidades de Conservação, trechos marginais arborizados (áreas de domínio de rodovias, encostas de barreiras, etc.), áreas particulares e públicas de uso restrito (sítios, quintais, jardins etc), além dos parques, praças, e jardins municipais, de uso público.

As áreas verdes trazem benefícios para a cidade tais como a melhoria do clima em 
escala local pela sombra que produzem, pela absorção dos raios solares e pela retirada do calor do ar através da evapotranspiração, servem de barreira contra o vento, reduzem a poluição sonora, organizam espaços, escondem elementos urbanos desagradáveis, protegem a biodiversidade, atuam no controle de pragas e doenças urbanas, colaboram com a drenagem das águas pluviais e com a recarga da água do solo e ainda trazem melhor convívio social, lazer, educação e prática de esportes (Meunier, 2000). Além disso, a arborização ajuda a caracterizar a paisagem das ruas, praças e parques, contribuindo para a noção de espaço ao ser humano e realçar o ambiente físico da cidade.

A cidade de São Paulo apresenta índice médio de áreas verdes/habitante de 4,9 m²/ hab, valor muito abaixo do mínimo recomendado nos estudos citados anteriormente, em torno de 12 a $15 \mathrm{~m}^{2} /$ habitante. Para efeito de comparação com grandes cidades, Buenos Aires apresenta índice de $9 \mathrm{~m}^{2} / \mathrm{hab}$, Curitiba, $16 \mathrm{~m}^{2} / \mathrm{hab}$, Londres, $71 \mathrm{~m}^{2} / \mathrm{hab}$ e Los Angeles, $111 \mathrm{~m}^{2} / \mathrm{hab}$ (EMPLASA, 2000).

\begin{tabular}{|c|c|c|c|}
\hline Ano & Áreas Verdes & População & Índice \\
\hline Anterior a 1860 & 143.428 & 31385 & 4,57 \\
\hline $1860-1890$ & 143.428 & 64.934 & 2,21 \\
\hline $1890-1920$ & 326.527 & 579.033 & 0,56 \\
\hline $1920-1950$ & 13.933 .627 & 2.189 .096 & 6,37 \\
\hline $1950-1980$ & 26.680 .135 & 8.493 .226 & 3,14 \\
\hline 1980-1996 & 37.084 .581 & 10.220 .783 & 3,63 \\
\hline
\end{tabular}

Em 2012, a prefeitura pretende atingir a marca dos 100 parques municipais, em um total de $48.684 .505,77 \mathrm{~m}^{2}$, número que não inclui os parques estaduais e as Áreas de Proteção Ambiental. Os novos parques, locados de forma mais equilibrada pelo território urbano, buscam reduzir o desequilíbrio na distribuição de áreas verdes do município (PMSP, 2008). Atingindo esta meta, a cidade passará a contar com um total de $86130542 \mathrm{~m}^{2}$ de áreas verdes públicas. Adotando-se uma população de 11,0 miIhões no município para 2012 (projeção SEADE, 2003), a taxa de área verde passará dos atuais $4,9 \mathrm{~m}^{2} / \mathrm{hab}$ para $7,8 \mathrm{~m}^{2} / \mathrm{hab}$. Este será um feito extraordinário, no entanto, atingir o valor mínimo recomendado, entre $12 \mathrm{~m}^{2} /$ habitante e $15 \mathrm{~m}^{2} /$ habitante, parece 
distante, em uma cidade já densamente ocupada onde poucas e pequenas são as áreas livres que podem ser destinadas a parques e praças sem a necessidade de desapropriações.

A atual má distribuição das áreas verdes influi em aspectos relacionados à qualidade de vida urbana. Algumas regiões são muito bem servidas, como a Capela do Socorro, apresenta taxa de $162 \mathrm{~m}^{2} / \mathrm{habitante}$; outras localidades são completamente nuas de vegetação. Segundo dados da Secretaria do Verde e Meio Ambiente - SVMA (2000), a região do Itaim Paulista, Brás e Santa Cecília, esta última objeto deste estudo, apresentam taxas de vegetação/habitante próximas de zero. De modo geral, a distribuição das áreas verdes está intimamente relacionada à questão habitacional. Nas áreas de predomínio de população de baixa renda observa-se o desrespeito ao percentual de área construída, gerando a carência de áreas verdes, onde as áreas verdes públicas já praticamente inexistem.

Luchiari (2001), verificou que em áreas residenciais a cobertura vegetal estava relacionada a qualidade de vida, nível sócio-econômico e nível de renda das populações urbanas.

Em áreas particulares também são observadas maiores quantidades de vegetação o que pode estar envolvido com descontos do IPTU para os terrenos que preservem áreas com vegetação em suas propriedades ( $\mathrm{NUCCl}$ et. al., 2003).A perda de cobertura vegetal nas grandes metrópoles do Brasil, como São Paulo, Rio de Janeiro e Belo Horizonte, com maior intensidade nos centros urbanizados, tem revelado um quadro ambiental preocupante conforme as séries históricas de mapeamento e quantificações de perdas do verde urbano (LUZ e RODRIGUES, 2007).

De forma a comprovar os dados da Secretaria do Verde e Meio Ambiente, esta pesquisa levantou as áreas verdes de um perímetro demarcado dentro do bairro de Santa Cecília, através de análise de imagens, seguindo a metodologia desenvolvida por Jim (1989).

Este pesquisador desenvolveu, em 1989, um estudo em Hong Kong no qual procurou classificar os tipos de configuração das manchas de cobertura vegetal, desta cidade, chamado de "Treecanopy- cover" (cobertura da copa das árvores), criando uma metodologia de fácil aplicação no reconhecimento dos sistemas de áreas verdes. Este estudo foi feito por meio de fotos aéreas na escala de 1:8.000 e projetadas em cartas 
planimétricas nas escalas de 1:2.500 e 1:5.000, reduzindo para escalas de 1:20.000 (Figura. 1).

\section{ISOLATED}
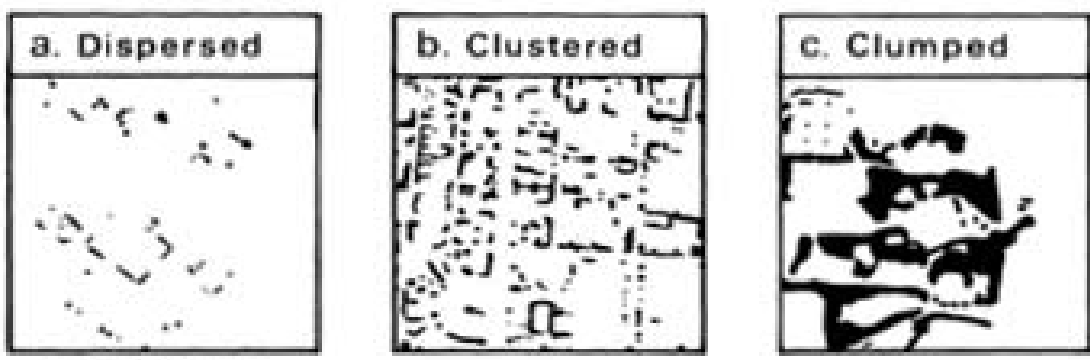

\section{LINEAR}
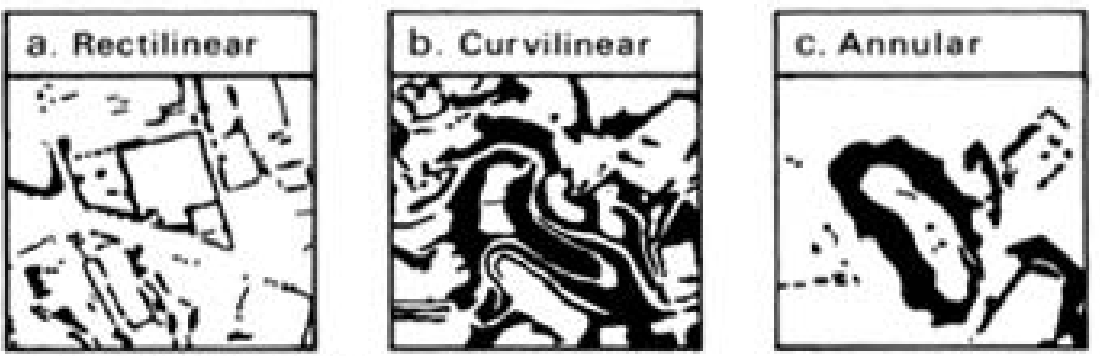

3. CONNECTED
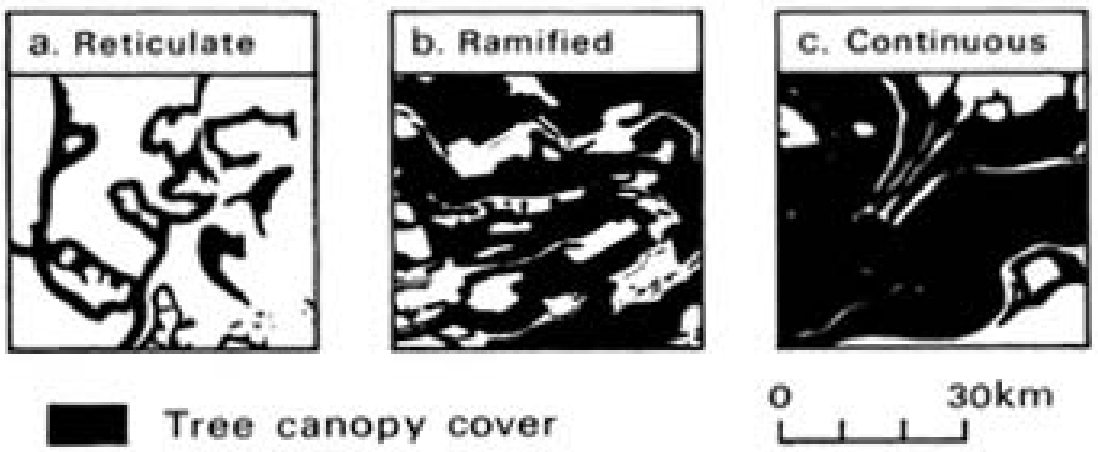

Vha. 6-Clasaification acheme for urtan tree canopy

Figura 1: Classificação da cobertura vegetal (Fonte Jim,1989 : 218)

Com base na análise da distribuição, conectividade e contiguidade da cobertura vegetal, Jim classificou as manchas de vegetação em três principais tipos:

1 "Isolated": há pequenos focos de cobertura vegetal, manchas predominante em locais pavimentados e edificados, como é o caso dos centros urbanos, com variações: "Dispersed", com pequenas manchas isoladas; "Clustered", encontram-se pequenos grupos de árvores; "Clumped", apresenta manchas de árvores bem agregadas.

2 "Linear": apresenta justaposição de árvores em uma direção dominante em diversos arranjos, com variações: "Rectilinear", estreito alinhamento ao longo das calçadas; 
"Curvilinear", apresenta-se em cinturões largos; e "Annular", onde as mancas formam um anel em torno de morros e montanhas.

3 "Connected": alto de grau de conectividade e contigüidade entre as manchas de cobertura vegetal, com variações: "Reticulate", apresenta uma rede alongada atravessando interstícios de vertentes não urbanizadas entre construções agrupadas; "Ramified", onde a área possui mais de 50\% de cobertura vegetal e "Continuous", em que a área possui mais de $75 \%$ de cobertura vegetal.

Adas (2007) analisou os estudos de Lobo et al. (2005), Nucci (2001) e Lopes e Fávero (2006) utilizando a metodologia de Jim.

Lobo et. al. (2005) realizou estudos na região central da cidade São Paulo e observou padrões de distribuição desconexa e fragmentada da cobertura vegetal. No subdistrito da Sé, por meio de fotos aéreas 1:6.000, a vegetação levantada correspondeu a 6,97\% da área estudada e apresentou padrão de distribuição predominante do tipo "Isolated".

Nucci (2001) fez um estudo no subdistrito de Santa Cecília, também no centro do município de São Paulo, na escala 1:10.000, em que 7\% da área de estudo é representada por cobertura vegetal e além disso, $78 \%$ da superfície é construída, $20 \%$ é representada pelo sistema de integração viária e apenas $2 \%$ são espaços livres públicos. Por sua vez, Lopes e Fávero (2006) estudaram a cobertura vegetal do subdistrito da Consolação (Centro/ MSP), na escala 1:6.000, que representou 26,9\% da área estudada e foi caracterizada como, predominantemente, do tipo "Isolated" apesar de apresentar muitas manchas do tipo "Clumped", devido às diversas praças e áreas tombadas encontradas neste bairro.

Usando esta mesma metodologia utilizou-se foto aérea, em escala 1:12.500, onde se demarcou as áreas verdes do limite de estudo diferenciando o verde viário, o verde público e o verde privado. Os estudo e análise são apresentados mais adiante. 


\section{HIDROGRAFIA}

Em relação á questão hídrica, a cidade de São Paulo teve praticamente todas suas áreas úmidas drenadas e aterradas. Ao longo dos anos, a expansão da cidade foi definida de maneira tecnocentrista(2), retificando e canalizando os rios, muitas vezes tamponados para dar espaço a grande avenidas de fundo de vale. Uma das grandes questões ambientais diz respeito à ocupação das várzeas, que traz diversos problemas para o município, desde a alteração da paisagem e comprometimento dos córregos, até as questões de inundações e seus conseqüentes prejuízos.

Com base nas características geomorfológicas do distrito de Santa Cecília, pode-se entender o comportamento da drenagem da área bem como os motivos da localização dos pontos de enchentes.

Segundo o Mapa Geomorfológico Esquemático do Sítio Urbano de São Paulo (Ab'Saber, 2007) o município de Santa Cecília abrange 3 morfo-unidades:

a) Terraços Fluviais do Nível Intermediário (745-750m), compreendendo as áreas popularmente conhecidas como "baixo Higienópolis", "Santa Cecília" e parte mais alta de "Campos Elíseos";

b) Baixos Terraços Fluviais do Vale do Tietê e seus afluentes principais (725- $730 \mathrm{~m})$ : "Campos Elíseos" e parte mais alta da "Barra Funda";

c) Planícies Aluviais do Tietê e seus afluentes, na "várzea da Barra Funda", divididos em dois níveis:

- Planícies de inundação, sujeitas apenas às grandes cheias (722-724m).

- Planícies de inundação, sujeitas a inundações anuais (719-721m).

O distrito de Santa Cecília apresenta, ao sul da linha férrea, um relevo não muito dissecado com cotas que variam de 760 a $725 \mathrm{~m}$. Ao norte da ferrovia, aos $725 \mathrm{~m}$, se inicia o trecho esquerdo da planície aluvial do rio Tietê que, sob a ponte da Casa Verde, atinge a cota $720 \mathrm{~m}$. 


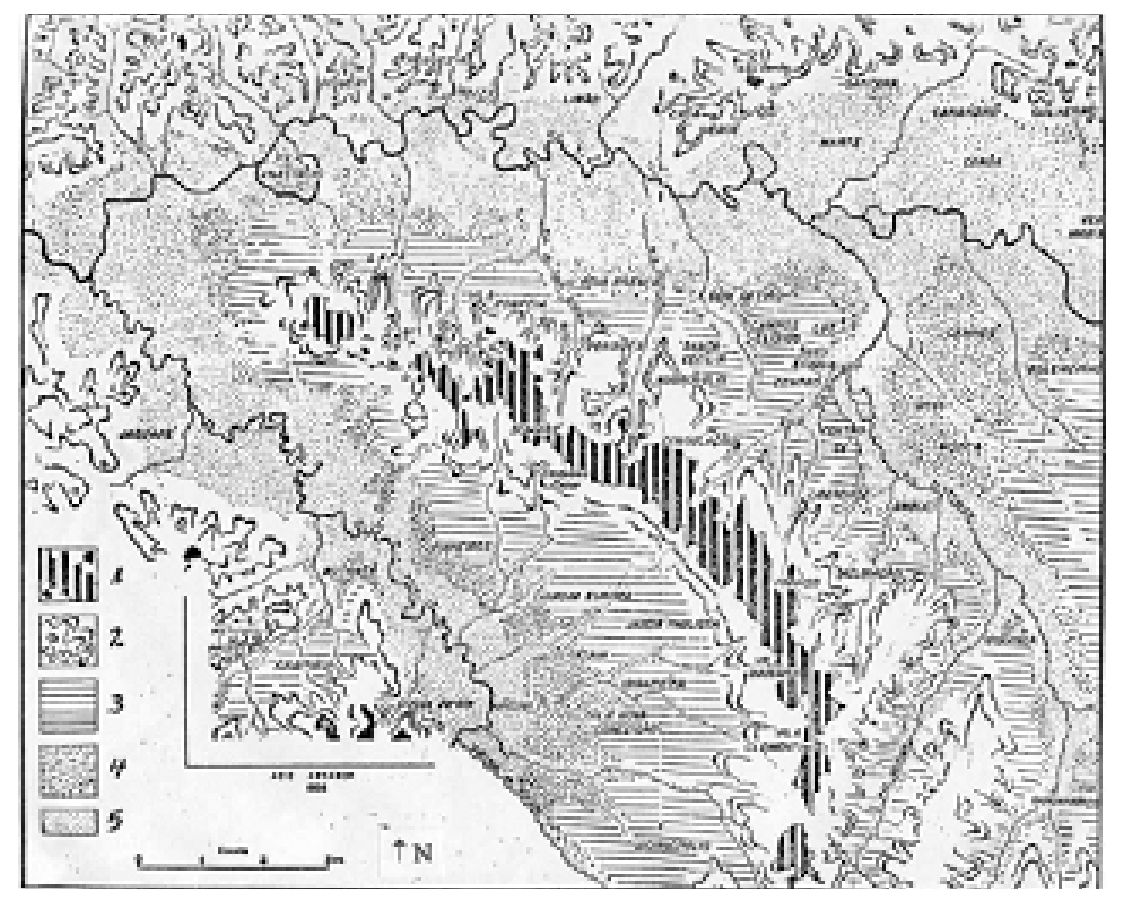

Figura 2: Mapa geomorfológico do sítio urbano de São Paulo (Ab'Sáber, 2007)

Nos pontos mais baixos do bairro existem três córregos principais, canalizados, que não apresentam suas nascentes dentro do distrito, mas em cotas mais elevadas, sendo eles o córrego do Arouche, o córrego do Pacaembú e um córrego central cujo nome não foi identificado (NUCCl, 2008), apresentados na figura 3(a).

Observa-se, no entanto que no mapa atual de micro-bacias do município de São Paulo, apresentado na figura 3(b), o distrito de Santa Cecília atravessa as micro-bacias do Pacaembú e do Anhengüera e o córrego do Arouche não aparece.

Nucci (2008) ainda fez um levantamento detalhado do caminhamento destes córregos e das áreas de drenagem. O córrego do Arouche nasce perto da igreja da Consolação. Após alcançar o largo do Arouche, onde formava uma lagoa, segue pela rua Frederico Steidel e recebe, ao chegar à av. São João, um afluente em sua margem esquerda. Segue em direção ao entroncamento das Alamedas Barão de Campinas, Nothmann e rua Dr. Carvalho de Mendonça, onde outro afluente deságua. Desse ponto continua em direção à ferrovia passando pelo cruzamento da av. Eduardo Prado com rua Conselheiro Nébias. Após a ferrovia, segue em direção ao norte, indo desaguar no Tietê.

O córrego mais central, de nome não identificado, nasce ao sul da nascente do córrego do Arouche, na mesma vertente norte da rua da Consolação e desce entre a alameda Albuquerque Lins e rua Basílio Machado. Após ultrapassar o Elevado Costa e Silva, perde velocidade e, ao entrar na planície aluvial, após a ferrovia, se dirige para o Tietê. 
O terceiro córrego, do Pacaembu, forma o limite oeste do distrito de Santa Cecília. Tem sua nascente na vertente norte do Espigão Central de São Paulo, na av. Dr. Arnaldo, descendo até a avenida Pacaembu, por onde segue com baixa energia. Após o Elevado Costa e Silva, encontra a planície aluviar e deságua no rio o Tietê.

Com base neste estudo de caminhamento destes córregos, Nucci (2008) analisou os principais pontos de enchentes da região.

O primeiro ponto, localizado no limite sudeste do distrito, divisa com o largo do Arouche, pode ser explicado devido à antiga lagoa aí existente anterior às obras de pavimentação, entre as cotas 745 e 735m com declividade baixa, onde as águas do córrego de Arouche se acumulam. O córrego do Arouche segue, então, para o segundo ponto de enchente na rua Frederico Steidel, devido à baixa declividade. Um terceiro ponto de baixa declividade ocorre no cruzamento das alamedas Barão de Campinas e Nothmann, onde antes da canalização observava-se amplas áreas de inundação natural.

Praticamente toda a água proveniente das chuvas ou dos edifícios das área de Campos Elíseos e da vertente leste do divisor sobre a av. Angélica, flui para o córrego do Arouche onde, devido à baixa declividade em alguns pontos, o córrego não corria encaixado em toda sua extensão e portanto suas águas acabavam se espalhando, ocupando assim suas margens quando ocorriam momentos de fortes chuvas. Com o passar do tempo o córrego do Arouche vem se tornando cada vez mais sobrecarregado em função da verticalização e da impermeabilização de suas margens e das vertentes a montante do mesmo.

Mais ao norte, junto à ferrovia, encontram-se as ruas Capistrano de Abreu, Conselheiro Brotero, Victorino Carmilo e Lopes Chaves, que também sofrem com os problemas das cheias. Essa é uma área de baixada para onde as águas do entorno, todo impermeabilizado, acabam convergindo com grande velocidade e ficam represadas pelos taludes da ferrovia, aumentado o potencial de enchente na região.

O córrego do Pacaembu corre para o norte, em direção ao Tietê, tendo em sua vertente direita o bairro de Higienópolis e depois Santa Cecília e na sua vertente esquerda o bairro de Perdizes e depois Barra Funda. Os bairros de Higienópolis e Perdizes se encontram totalmente impermeabilizadas e muito verticalizados, o que produz uma vazão muito superior àquela natural, absorvida pela calha do rio. Após atravessar a av. 
Gal. Olímpio da Silveira, o córrego do Pacaembu formava uma ampla lagoa natural. O trecho da av.Pacaembu, desde a rua Dr. Veiga Filho até a ferrovia, sofre com as enchentes, bem como o entorno do Memorial da América Latina, uma enorme área impermeabilizada construída sobre a planície aluvial. Ao norte da ferrovia o gradiente de declividade torna-se muito baixo; com cotas variando entre 725 a 720m, em uma grande extensão. Essa área foi arruada e edificada na medida em que a planície aluvial do Tietê, com seus amplos meandros, foi sendo drenada e aterrada.

Segundo o mapa da Sara Brasil (1930), percebe-se que da av. Marquês de São Vicente para o norte existia um amplo brejo com depressões periodicamente inundadas. A av. Rudge já existia e, praticamente, $30 \%$ da área já estavam ocupados. É interessante notar que na região se encontram ruas com nome relacionados com cheias, como rua Baixa e rua da Várzea, esta última localizada bem sob o viaduto Pacaembu logo após a ferrovia, indicando assim a existência nesse local da planície aluvial ou popularmente conhecida como várzea.

Mesmo a área da várzea sendo local de inundação do rio Tietê, obras de engenharia, como arruamentos, aterros, canalizações, fizeram com que alguns pontos ficassem a salvo das enchentes, todavia a água que ocuparia esses locais acaba fluindo e se acumulando nas cotas mais baixas. A rua James Holand, entre a rua do Bosque e av. Marquês de São Vicente, é um desses pontos de inundação.

Analisando-se o sentido dos fluxos da água com base nos pontos cotados, percebese que a av. Marquês de São Vicente, construída em uma cota mais alta do que a rua James Holand, forma um dique fazendo com que a água se acumule nesta última. Outra área de cheia que apresenta mesma explicação é a que abrange as ruas James Holand, Solimões, Baronesa de Porto Carreiro, dos Americanos e Geraldo Buono, no extremo norte do distrito.

Com a eliminação de antigos meandros e com o aterro para a construção das marginais do Tietê, criou-se uma bacia na qual a água passou a se acumular com mais vigor. 


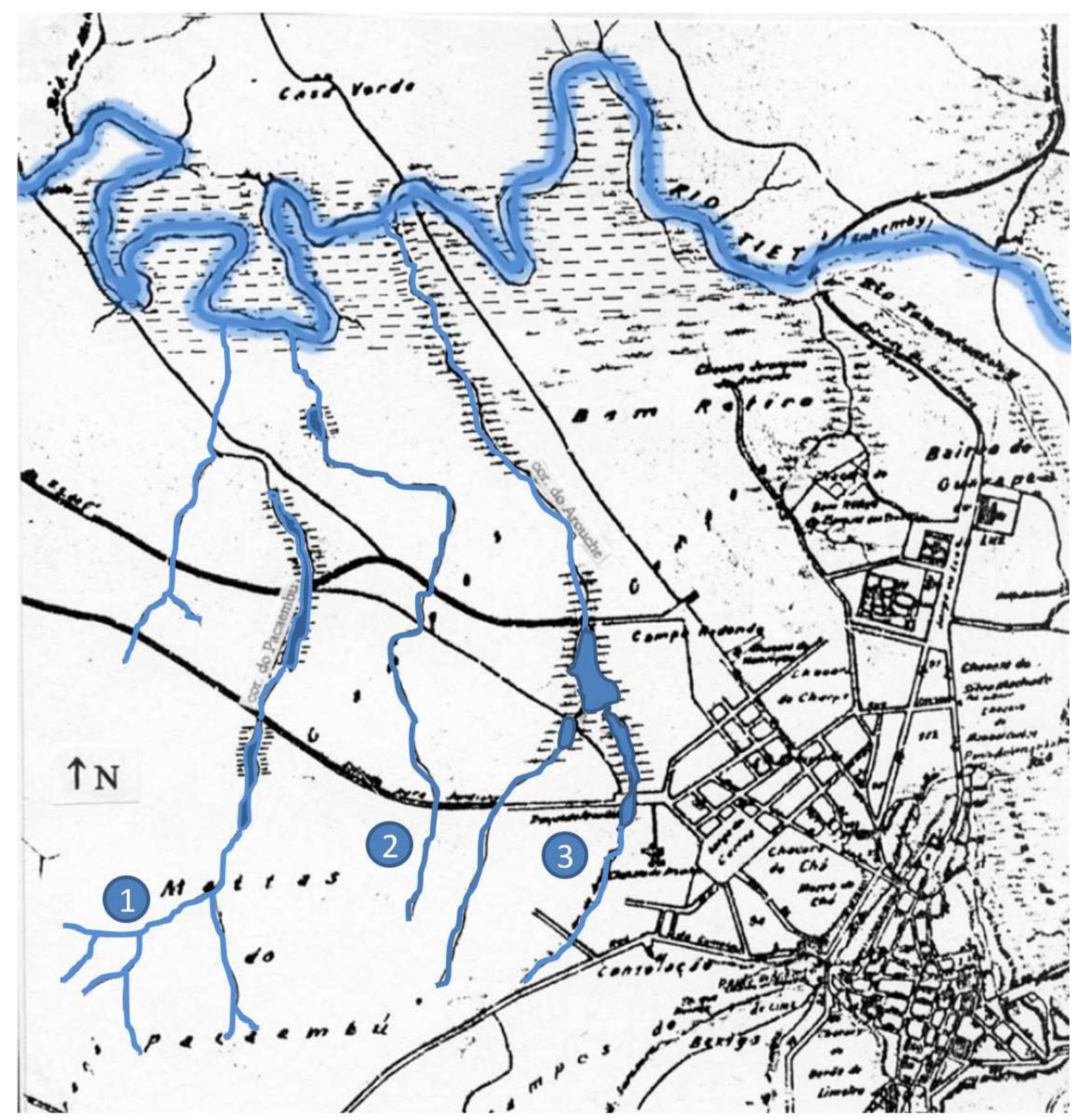

(1) Córrego Pacaembu

(2) Córrego não identificado

3 Córrego Arouche 
Detalhe do mapa de micro bacias hidrográficas do município de São Paulo
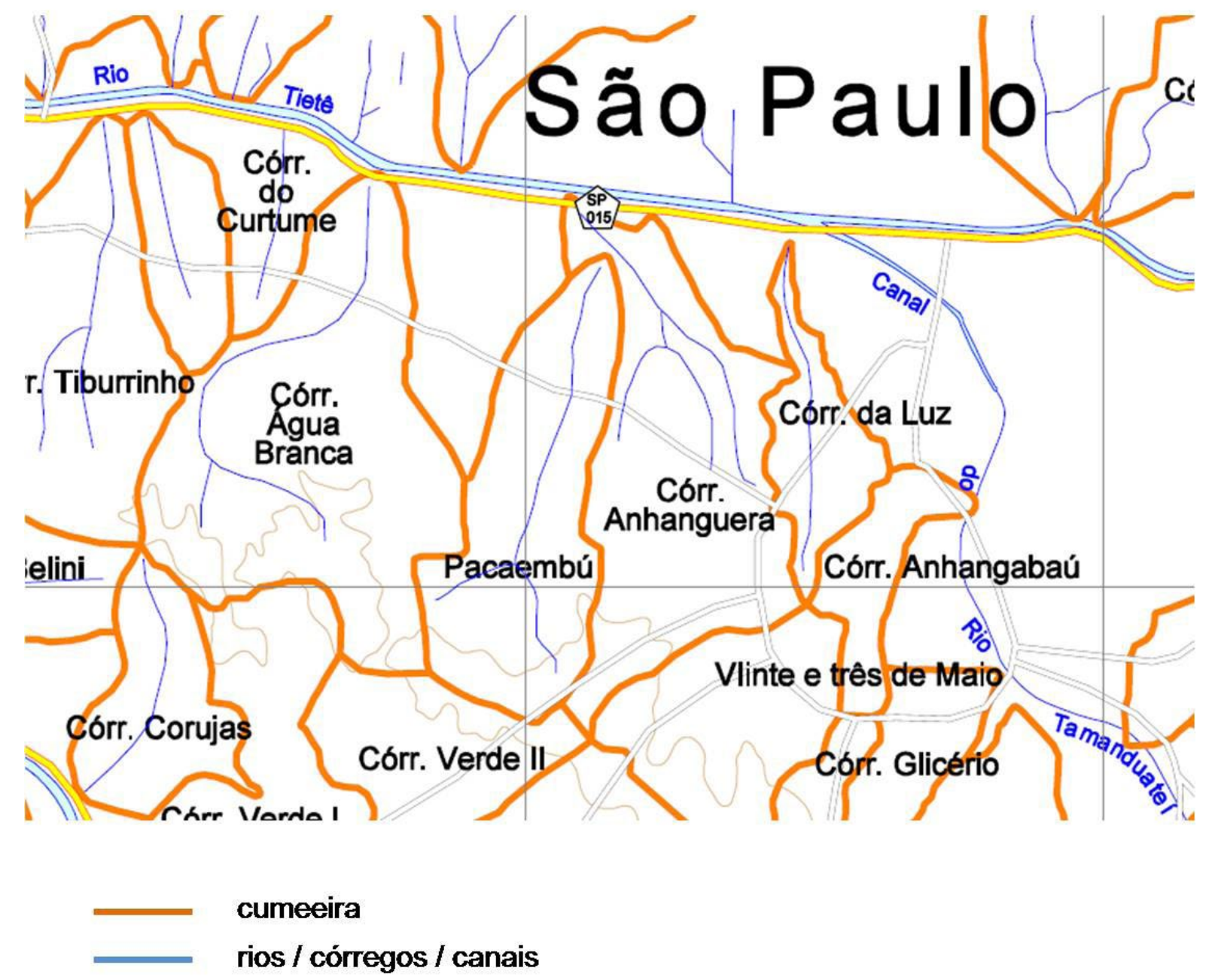

Fonte: PMSP / SVMA - DEAPLA, fornecido em 28/11/2006

Figura 3: Localização dos córregos dentro do distrito de Santa Cecília

(a) em 1840 Fonte :"Planta da Cidade de São Paulo de 1840, reconstrução histórica e topográfica aproximada. in NUCCI , 2008.

(b) em 2002 Fonte: Mapa de micro-bacias do Município de são Paulo PMSP/SVMADEAPLA (fornecido em 28/11/2006)

Observa-se que a ocupação das cotas superiores no bairro de Santa Cecília influencia toda a dinâmica do distrito. Áreas localizadas a montante dos pontos de enchente devem diminuir o grau de verticalização e impermeabilização do solo aumentando a quantidade de áreas livres de construção permeáveis e vegetadas. A ocupação das planícies aluviais com edificações e impermeabilização do solo provoca transtornos que dificilmente poderão ser resolvidos sem se gastar uma grande quantia em dinheiro e com um prejuízo emocional e material para a população que ali vive. 


\section{CONFORTO TÉRMICO - BANDA TERMAL}

As cidades apresentam, em função de suas edificações e densidade de área construída, impermeabilização do território e das alterações da paisagem feitas pelo homem, A lha de calor ou ilha de calor urbana (ICU) é uma designação dada à distribuição espacial e temporal do campo de temperatura sobre a cidade que apresenta um máximo, como se fosse uma ilha quente localizada sobre determinada localização geográfica. Alterações da umidade do ar, da precipitação e do vento também estão associadas à presença de ilha de calor urbana.
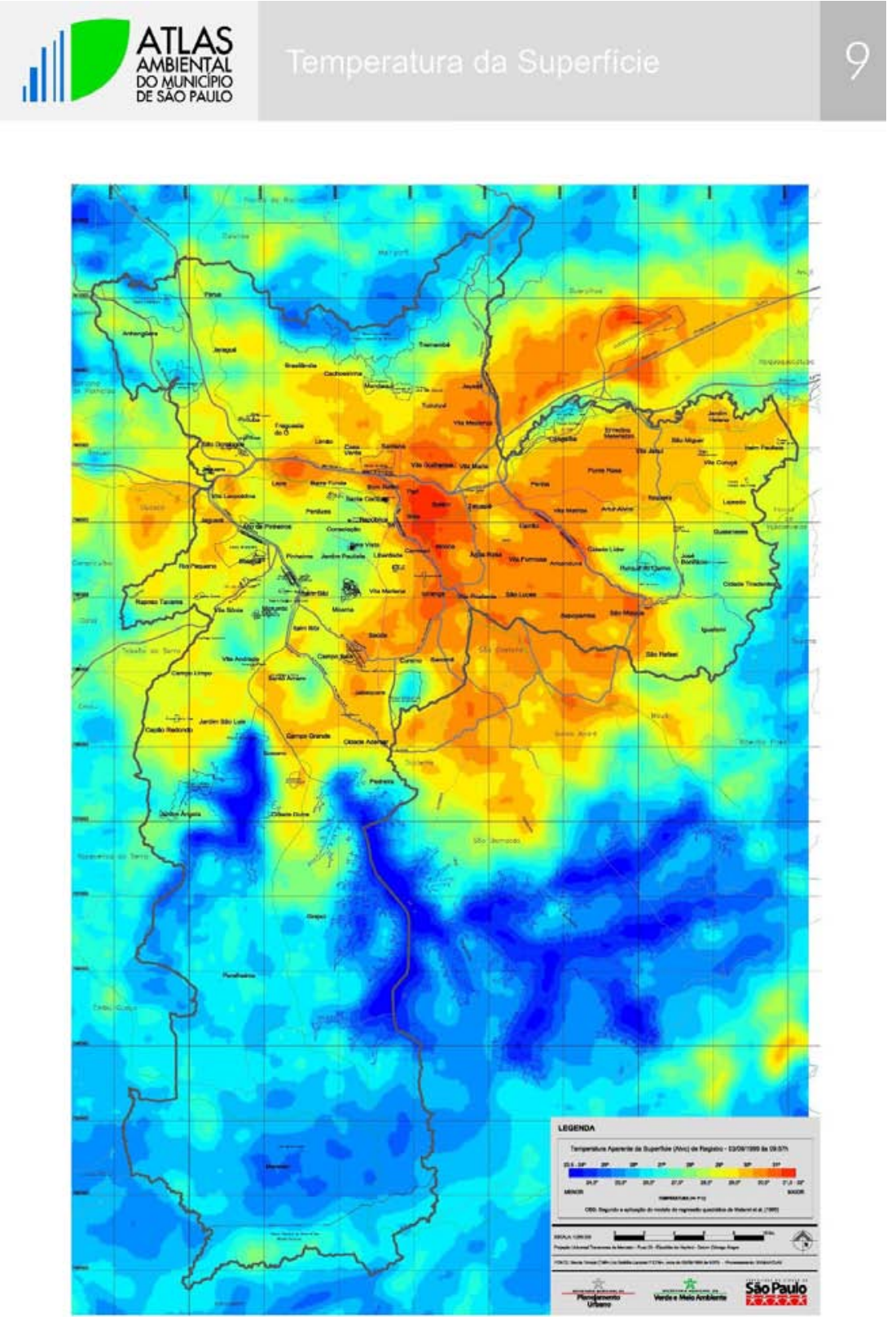

Figura 4 : Temperatura da superfície Fonte:

Atlas Ambiental de São Paulo (2002). 
Desta forma, as áreas mais adensadas, impermeabilizada em sem cobertura vegetal ou presença de rios, apresentam temperaturas superiores às áreas que não possuem essas condições tão exacerbadas.

\section{ÁREA DE ESTUDO}

A área de estudo se localiza dentro do distrito de Santa Cecília. A figura 5 abaixo apresenta a imagem de satélite com a locação dos limites da micro-bacia do córrego Anhangüera e o limite do distrito de Santa Cecília, bem como o limite da área de estudo.

Observa-se que o distrito, ao atravessar duas micro-bacias, não respeita a unidade mínima de gestão ambiental que é a micro-bacia.

No mapa da figura 5 abaixo, observa-se uma linha vermelha dando o limite da microbacia do córrego Anhanguera, onde se localiza a área de estudo. As manchas verdeclaro dizem respeito às massas verdes arbustivas e as manchas verde-escuro identificam as massas verdes arbóreas.

A tabela 2 a seguir resume os dados levantados:

\begin{tabular}{|l|l|}
\hline \multicolumn{2}{|c|}{ Distrito de Santa Cecília } \\
\hline Área total $\left(\mathrm{m}^{2}\right)$ & $3.869 .023,94$ \\
\hline Área de massa verde arbórea $\left(\mathrm{m}^{2}\right)$ & $198.342,26$ \\
\hline Área de massa verde arbustiva $\left(\mathrm{m}^{2}\right)$ & $147.057,76$ \\
\hline Área verde total $\left(\mathrm{m}^{2}\right)$ & $345.400,02$ \\
\hline População (habitantes - SEADE, 2008) & 71179 \\
\hline Índice de áreas verdes (m²/hab) & 5,3 \\
\hline Tabela 2: Quantificação das áreas verdes no distrito de Santa Cecília
\end{tabular}




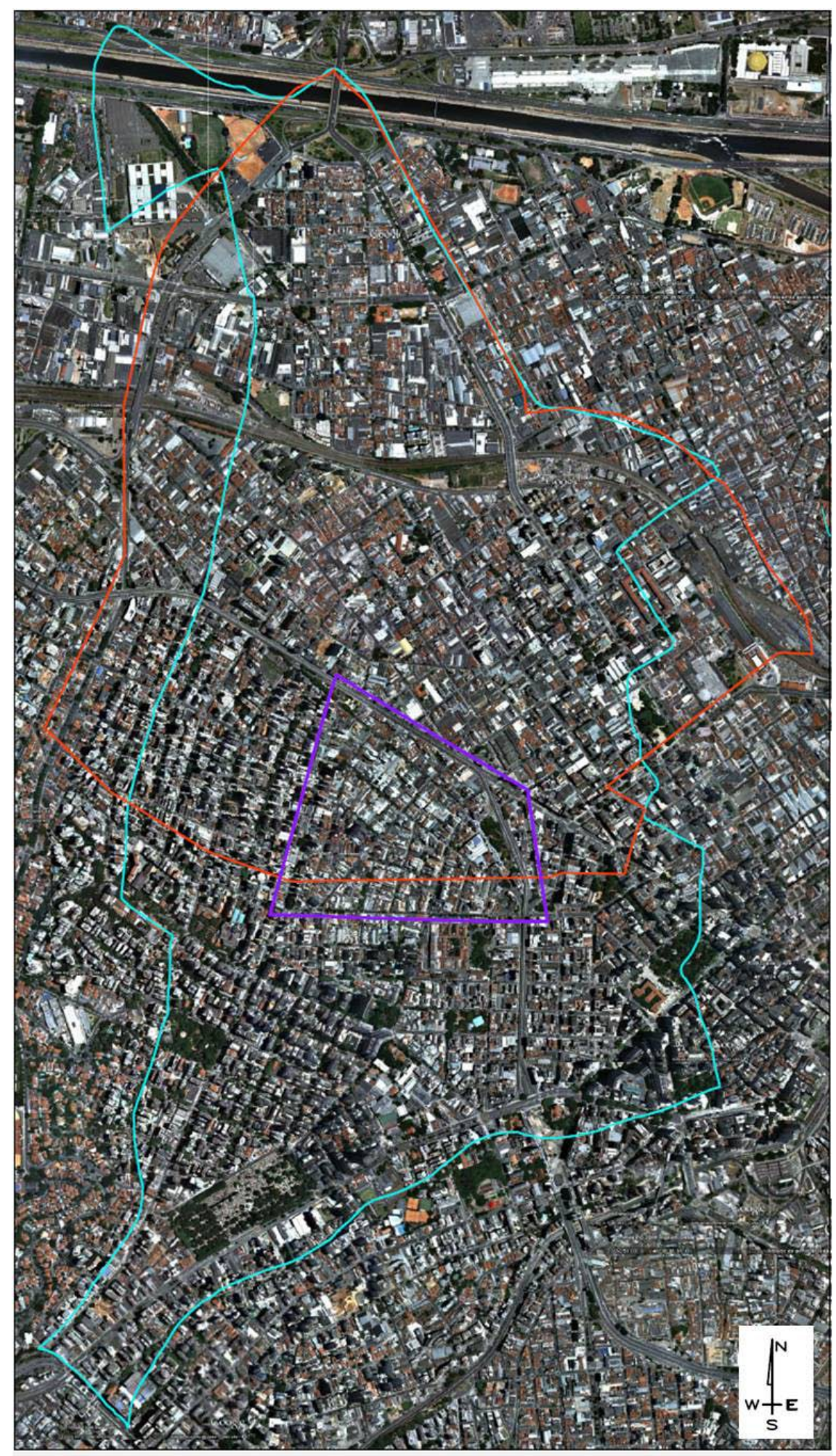

$\begin{aligned} & \text { Limitedo Distrito } \\ & \text { Santa Cecilia }\end{aligned}-\begin{aligned} & \text { Limite abrangente } \\ & \text { da área de estudo }\end{aligned}-\begin{aligned} & \text { Limiteda micro bacia } \\ & \text { do córrego Anhanguera }\end{aligned}$

Figura 4: Limites do distrito de Santa Cecília, da Bacia do córrego Anhanguera e da área de estudo sobre imagem de satélite, escala 1:12.500 Fonte: http://maps.google. com.br 


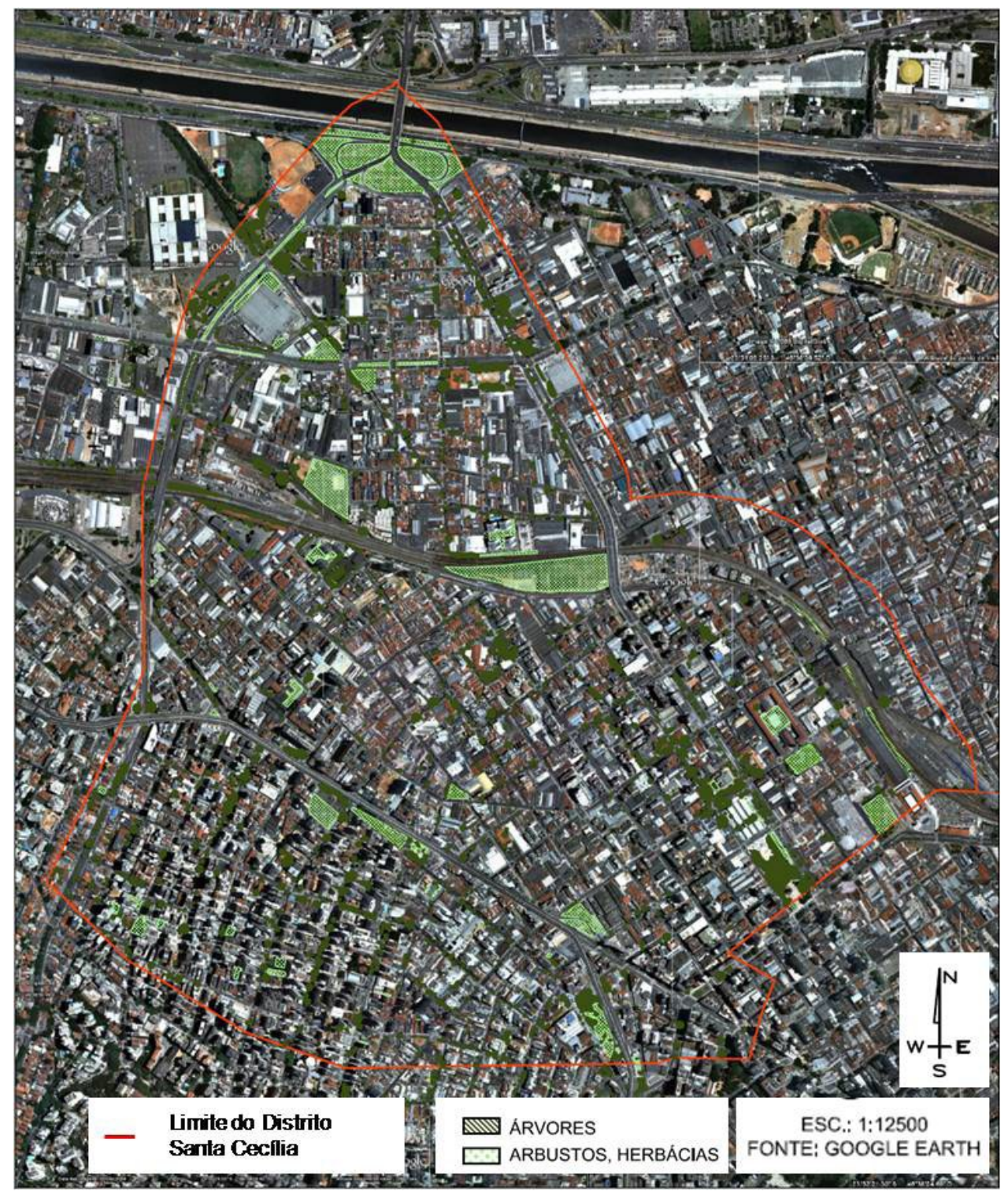

Figura 5: Localização das massas verdes dentro do limite do distrito de Santa Cecília sobre imagem de satélite, escala 1:12.500 Fonte: http://maps.google.com.br

Observa-se, desta forma que o distrito de Santa Cecília apresenta uma razão de área verde de $8,9 \%$, onde esta vegetação se classifica, segundo a metodologia de Jim (1989) como "isolated-clustered", com pequenos focos de cobertura vegetal e manchas predominante em locais pavimentados e edificados, com pequenos grupos de árvores. 
Em relação à área de estudo, foi efetuado o mesmo levantamento, mostrado na figura 6. A tabela 3 resume os dados obtidos:

\begin{tabular}{|l|l|}
\hline \multicolumn{2}{|c|}{ Área de Estudo } \\
\hline Área total $\left(\mathrm{m}^{2}\right)$ & $482.148,28$ \\
\hline Área de massa verde arbórea $\left(\mathrm{m}^{2}\right)$ & $30.490,60$ \\
\hline Área de massa verde arbustiva $\left(\mathrm{m}^{2}\right)$ & $4.592,22$ \\
\hline Área verde total $\left(\mathrm{m}^{2}\right)$ & $35.082,82$ \\
\hline Tabela 3: Quantificação das áreas verdes no distrito de Santa Cecília \\
\hline
\end{tabular}

O perímetro de estudo apresenta razão de área verde de 7,27\%, em função de uma menor concentração de grandes maciços de verde viário na área.

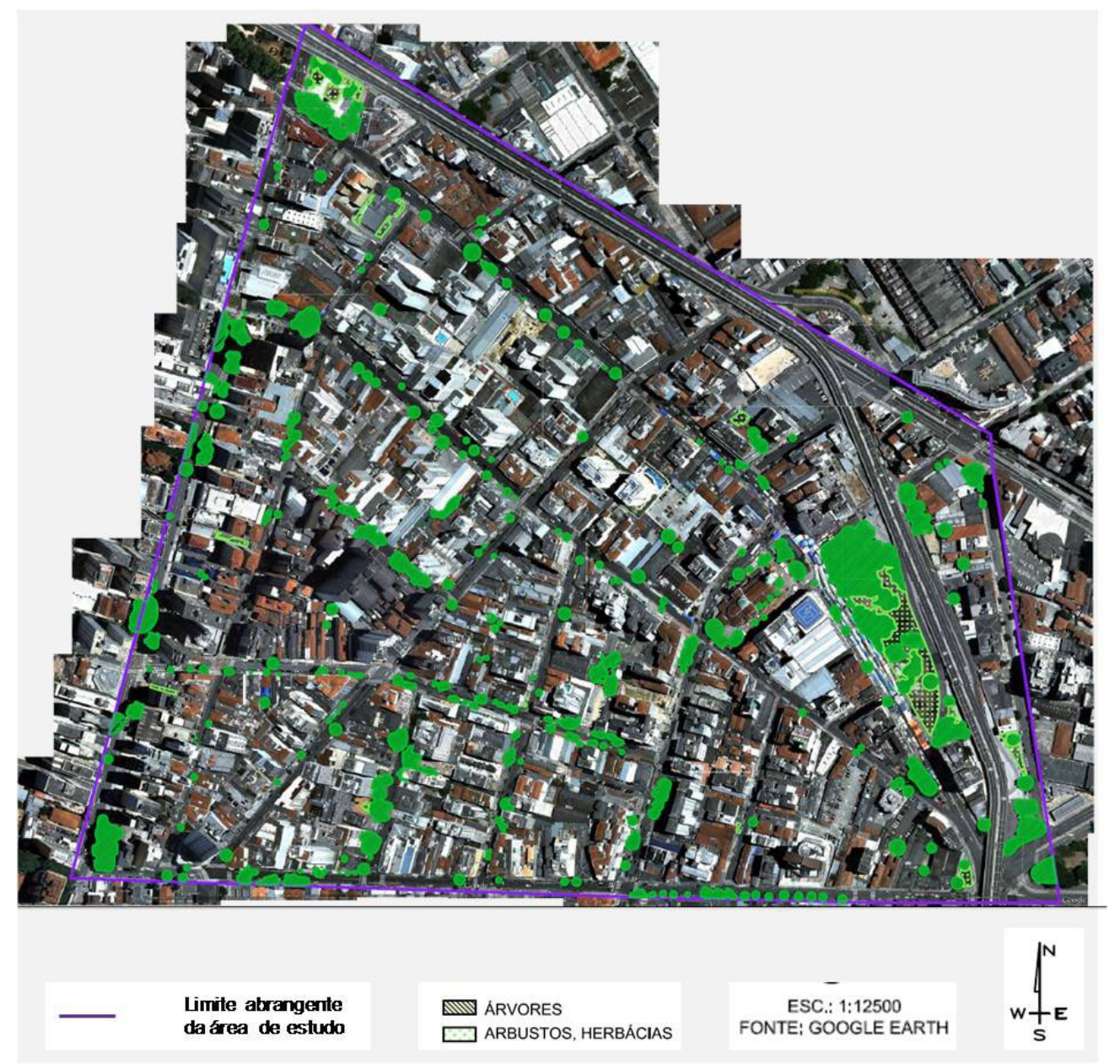

Figura 6: Localização das massas verdes dentro do limite de estudo sobre imagem de satélite, escala 1:12.500 Fonte: http://maps.google.com.br 
Em relação á banda termal, a figura 7, a seguir, mostra as temperaturas médias de superfície do município de São Paulo, medidas no dia 03/09/1999 às 09:57 h. Observase que no centro da cidade aparecem áreas de temperaturas mais elevadas, em torno de $30^{\circ} \mathrm{C}$. O distrito de Santa Cecília apresenta temperaturas entre 27,5 e $28^{\circ} \mathrm{C}$. Este valores elevados se devem, em parte, à baixa porcentagem de cobertura vegetal na área e à ausência da exposição das águas dos rios e córregos. Outros fatores influentes tais como o adensamento, a ocupação das várzeas, a impermeabilização do solo, correntes de ar e relevo não foram levantados de forma que não se pode discutir seu grau de importância.

Bairros próximos, como Consolação e Bela Vista, tão adensados quanto Santa Cecília, apresentaram no mesmo dia e horário, temperaturas em torno de $26^{\circ} \mathrm{C}$, no caso, em função da maior porcentagem de vegetação e do relevo.

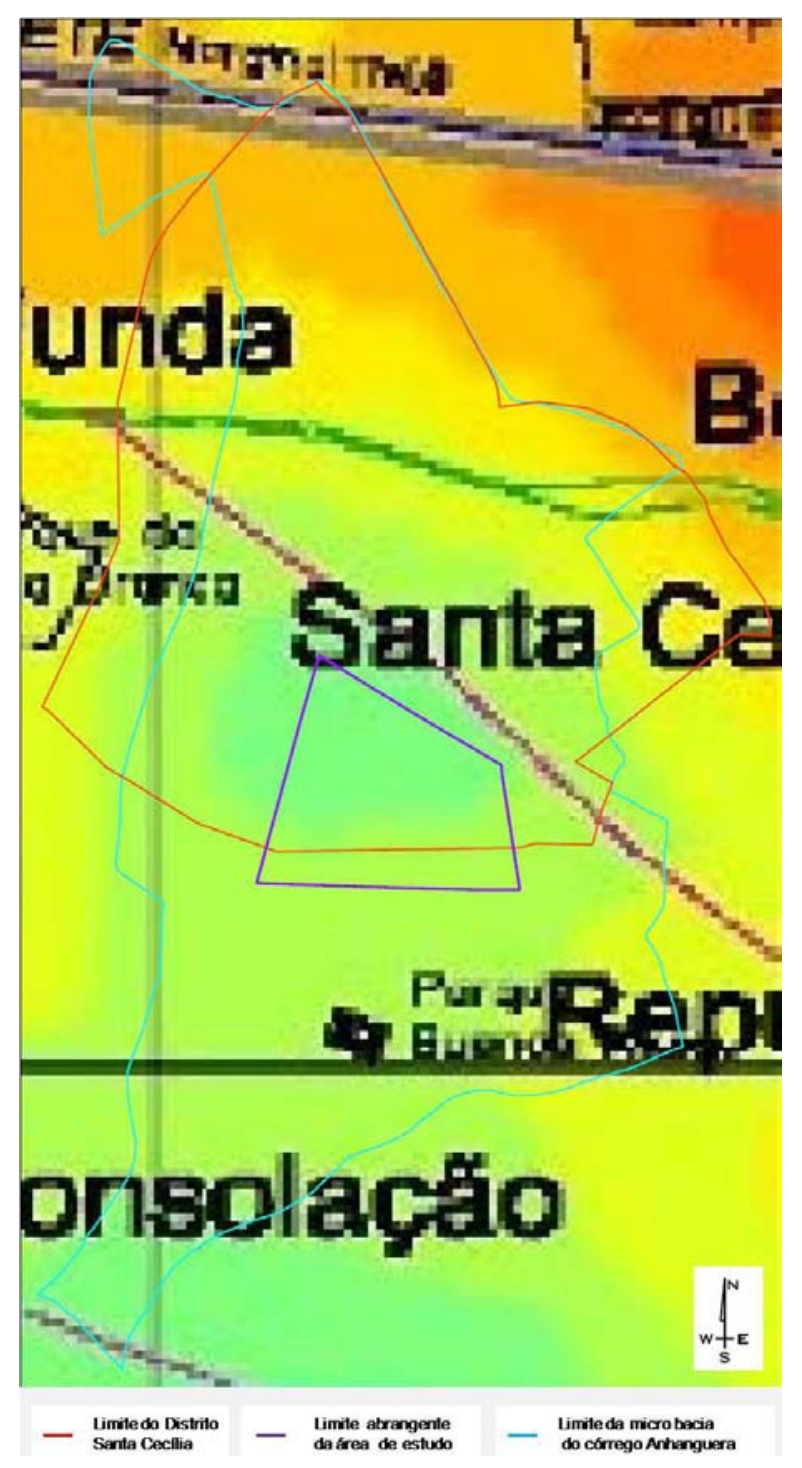

Figura 7: Temperatura da superfície Fonte: Atlas Ambiental de São Paulo (2002) 


\section{RESULTADOS}

Considerando as questões ambientais levantadas observa-se que os limites do distrito de Santa Cecília não foram traçados em conformidade com o limite de micro-bacias, consideradas a menor unidade de gestão ambiental, demonstrando a inexistência de um planejamento ambiental para as políticas publicas e administrativas no planejamento do uso e ocupação do solo.

Em relação às áreas verdes, apesar do trabalho contestar as definições de índices adequados de áreas verdes por habitante, também se vale dos mesmos para analisar a qualidade ambiental em relação a este parâmetro, mostrando que a região encontra um déficit de área verde/habitante em relação a qualquer um dos parâmetros adotados.

Em relação às questões hídricas, observa-se a ausência de rios e córregos expostos, onde os mesmos foram eliminados da paisagem, convertidos em um sistema de macro-drenagem, onde, no entanto, se observa que as águas não encontram mais o espaço para espraiamento nas antigas várzeas no distrito estudado, produzindo parte das cheias do município de São Paulo.

A ausência de um sistema de umidificação e refrigeração, parte em função da pouca vegetação e a ausência de águas, se traduz em temperaturas de superfície elevadas no local de estudo, causando desconforto térmico aos usuários e moradores da área.

Definitivamente o estudo das mudanças climáticas globais ou locais, é uma necessidade contemporânea e neste sentido, este trabalho propõe um melhor aproveitamento do potencial natural do território, preservando os benefícios da cobertura vegetal e da hidrografia, com forma de manter a qualidade ambiental urbana, estimulando sistemas de parques e áreas verdes, ao longo dos rios e córregos, proporcionando espaços públicos de alta qualidade, com a exposição das águas, resgatando a identidade da paisagem e o convívio com a vida silvestres em áreas urbanas.

\section{REFERÊNCIAS BIBLIOGRÁFICAS}

ADAS, Mariana Amélia Arantes: Estudo da cobertura vegetal no subdistrito da República (São Paulo/SP). Monografia de Conclusão de Curso, CCBS UPM, 2007. 
BROCANELI,P.F.; STUERMER, M.M. : Renaturalização de rios e córregos no município de São Paulo 3 Fórum de Pesquisa FAU Mackenzie, 2006.

DRAMSTAD, Wenche E.; OLSON, James D. e FORMAN, Richard T. T. Landscape Ecology Principles in Landscape Architecture and Land-Use Planning. Washington, DC: Harvard University Graduate School of design, Island Press and American Society of Landscape Architects, 1996.

JIM, G.Y., Tree-Canopy Covercharacteristics and urban development in Hong Kong. The Geographical Review, v79, n.2. Lawrence: American Geographical Society, pp 210-225, 1989.

KOHLER Maria Claudia Mibielli, ROMERO Marcelo de Andrade, PENHALBER Elizabeth de Faria, CORTES Maria Teresa Miraglia, CABRAL Viviane Benini. Áreas verdes no município de São Paulo: análises, tendências e perspectivas in:XXVIli Congresso linteramericano de Engenharia Sanitária e Ambiental, Porto Alegre, RS, 2000.

McHARG, Ian L. Proyectar con la naturaleza. Barcelona: Gustavo Gili, 2000.

MEUNIER, Isabelle - Jornal do Commercio - Caderno Cidades - Página Ciência e Meio Ambiente - Coluna "De Olho na Ciência"11 de junho de 2000

NUCCl, João Carlos Qualidade ambiental e adensamento urbano: um estudo de ecologia e planejamento da paisagem aplicado ao distrito de Santa Cecília (MSP), 2a ed. - Curitiba: O Autor, 2008.150 p.; il.

ODUM, Eugene Pleasants. Ecologia. Rio de Janeiro: Guanabara Koogan,1988.

1 AB'SABER, Aziz Nacib. Os Domínios de Natureza no Brasil: potencialidades paisagísticas. São Paulo: Ateliê Editoral, 2003. 